\title{
Elevated blood eosinophil count and exacerbations of COPD
}

Chronic obstructive pulmonary disease (COPD) is a major cause of global morbidity and mortality, currently listed as the fourth-leading cause of death. Exacerbation is the foremost contributor to worsening lung function, impairment in quality of life, need for urgent care or hospitalisation and cost of care in COPD. ${ }^{[1]}$ Factors predicting exacerbation frequency and thus providing subsequent optimal treatment strategies are presently a major focus in respiratory research.

Watz et al. ${ }^{[2]}$ reported on a post-hoc analysis of the WISDOM trial. ${ }^{[3]}$ In this 1-year, double-blind, parallel-group study, 2485 patients with severe COPD were enrolled, and inhaled corticosteroids (ICS) were withdrawn in one group over a 12 -week period. The trial showed a similar time to first exacerbation in both groups but a significant $(40 \mathrm{~mL})$ drop in forced expiratory volume in 1 second $\left(\mathrm{FEV}_{1}\right)$ in the ICS withdrawal group. When stratifying this cohort of patients according to the blood eosinophil count, those with an elevated count $>2 \%$ ( $46 \%$ of subjects) had a significant increase in the rate of moderate or severe exacerbations, with a rate ratio of $1.22(95 \%$ confidence interval (CI) 1.02 - 1.48), while an eosinophilia of $\geq 4 \%$ had a rate ratio of 1.63 (95\% CI $1.19-2.24$ ) and a blood eosinophil count of 300 cells/ $\mu \mathrm{L}$ reached statistical significance. Interestingly, neither atopy nor IgE were predictive of exacerbations after withdrawal of ICS.

There remain many unanswered questions, such as the optimal dose of ICS required to attenuate eosinophilia. To date, there is no plausible biological mechanism to explain this association between blood eosinophils and ICS response. The peripheral blood eosinophil count appears to correlate with sputum eosinophilia and eosinophilic inflammation. ${ }^{[4]}$ However, treatment with ICS does not appear to lower the blood eosinophil count ${ }^{[5]}$ and this may point towards a nonIgE mediated anti-inflammatory effect.

Peripheral blood eosinophilia is a convenient biomarker to measure, with clear cut-off values that may potentially be used to select patients that benefit from ICS use for exacerbations and other endpoints of clinical efficacy in COPD.

\section{Morné Vorster}

Pulmonology Fellow, Division of Pulmonology, Department of Medicine, Stellenbosch University and Tygerberg Academic Hospital, South Africa

1. Vedel-Krogh S, Nielsen SF, Lange P, Vestbo J, Nordestgaard BG. Blood eosinophils and exacerbations in chronic obstructive pulmonary disease. The Copenhagen General Population Study. Am J Respir Crit Care Med 2016;193(9):965-974. DOI:10.1164/ rccm.201509-1869OC

2. Watz H, Tetzlaff K, Wouters EFM, et al. Blood eosinophil count and exacerbations in severe chronic obstructive pulmonary disease after withdrawal of inhaled corticosteroids: A post-hoc analysis of the WISDOM trial. Lancet Respir 2016;4(5):390-398. DOI:10.1016/S2213-2600(16)00100-4

3. Magnussen H, Disse B, Rodriguez-Roisin R, et al. Withdrawal of inhaled glucocorticoids and exacerbations of COPD. N Engl J Med 2014;371(14):1285-1294. DOI:10.1056/NEJMoa1407154

4. Singh D, Kolsum U, Brightling CE, Locantore N, Agusti A. Eosinophilic inflammation in COPD: Prevalence and clinical characteristics. Eur Respir J 2014;44(6):1697-1700. DOI:10.1183/09031936.00162414

5. Barnes NC, Sharma R, Lettis S, Calverley PM. Blood eosinophils as a marker of response to inhaled corticosteroids in COPD. Eur Respir Journal 2016;47:1374-1382. DOI:10.1183/13993003.01370-2015

S Afr Respir J 2016;22(3):77. DOI:10.7196/SARJ.2016.v22i3.92 